\title{
A design of LED driver circuit for reducing production cost in Thailand industry
}

\author{
Chantima Lapsongphon, and Saroj Pullteap* \\ Mechanical Engineering Department, Faculty of Engineering and Industrial Technology, Silpakorn University (Sanam Chandra Palace), \\ Nakhon Pathom, Thailand.
}

\begin{abstract}
In this paper, the designing of a modified flyback converter circuit for 100 Watts LED lighting has been demonstrated. Some important factors, i.e. efficiency $(\varepsilon)$, power factor $(P F)$, and total harmonic current distortion $(T H D i)$, are considered for interpreting the performance of the proposed circuit. A commercial driver circuit which an efficiency of $94 \%$ and price of 2,000 THB has, consequently, been employed as a reference circuit. Two experimental setups, performance investigation and cost analysis, have been demonstrated for confirming the concept designed. However, the experimental results shown that an efficiency of the developed driver is $93.93 \%$, while the implementation cost is 1,257 THB respectively. Compared with the reference circuit, we found that the performance of modified flyback circuit is almost equivalent in any parameters, while the cost is cheaper than the reference of $37.15 \%$. This implies that there is a possibility to transfer the knowledge of designing concept to mass production for Thailand industry. In addition, it would thus be reduced the investment cost by the importation driver circuits from other countries and also to support Thailand industry for producing the high quality goods for exporting aboard.
\end{abstract}

\section{Introduction}

Nowadays, the light emitting diodes (LED) lighting is well known as an "energy saving lighting" It's cause to there are many advantages over the bulb lighting such as lower energy consumption ( $90 \%$ more efficient), longer life spans (about 60,000 hours), higher safety, and lower maintenance requirements, etc [1]-[3]. Consequently, the proposed lighting is becoming popular equipment for using in the human life. However, the global lighting market is reported that the proportional usage of the LED lighting accounted for $30 \%$ of the total lighting [4]. From the purpose, the LED lighting can, increasingly, be extended to grow up in the future. However, the LED lighting production of Thailand industry has been imported many LED components such as chip LED, LED driver circuit from the foreign countries for a long time. It causes to insufficient of technology and less production volume to their produce. This effects to the industry of Thailand for losing some the budgets from the imported goods amounting in several million baht per year, and also affected on the consumers in terms of expensive goods. In recent year, several research works have been focused on the development of LED driver with different techniques for improving their efficiency such as A. Pollock was designed a high efficiency buck converter circuit for LED power supply in automotive system [5]. The results show that the proposed circuit offered efficiency of LED driver as 95\%, which increased up to $3 \%$. In addition, Y. Wang developed a LED driver based on the $B C M$ boost circuit and $L L C$ converter for a street lighting system. In the proposed circuit, two integrated switches were available for improving the reliability of the system [6]. It offered the efficiency of prototype as high as $91.1 \%$, THDi of $20.2 \%$ and also a power factor $(P F)$ of 0.98 under the full load condition. Furthermore, C. Cheng was presenting a novel LED driver circuit by combining a dual buckboost $P F C$ controller with the coupled inductors and half bridge type of the $L L C$ resonant converter into a single stage power conversion circuit. However, the results demonstrated the high efficiency, high $P F$, and low $T H D$ of input utility line current which $<5.5 \%$, respectively [7]. Regarding to M. Arias work, he was studied the high efficiency LED driver without the electrolytic capacitor for a street lighting. The proposed circuit can be separated in three stage solutions i.e. $P F C$ boost converter, galvanic isolation with transformer, and two input buck converter, respectively [8]. Experimental results show the efficiency as high as $93 \%$ for the whole topology and $95 \%$ for the cascade connection of the second and third stages. From the above mentioned, it was found that these drivers could not be able to sell into the market due to over qualify and high cost.

In this research presents the designing of a LED driver circuit for reducing a production cost by comparing with a commercial LED driver circuit. According to the designed circuit, a modified flyback converter has been considered. To study the experiment, the implementation process has been employed for investigating the results of the electrical performances and also cost analysis respectively. However, the

*Corresponding author: saroj@su.ac.th 
experimental results are expected to become a major kind of trend for reducing the importation of driver circuits from the foreign suppliers. Moreover, the research output also make the LED operation cost in Thailand industry would be decreased.

\section{Overviews of LED driver circuit}

\subsection{Principle of LED driver circuit}

The LED driver circuit is an important part of LED lighting system. It is the electronic parts that converts the $\mathrm{AC}$ power into the proper DC voltage and regulates the current flowing through the LED during operation, like a ballast of fluorescent lamp [9]. Normally, the switching power supply can be applied for the LED driver circuit. It is containing of the converter circuits, which are an important factor to provide the efficient of whole LED lighting systems.

\subsection{Mofidifed flyback converter circuit designing}

Normally, the designing of modified flyback converter uses the multiphase of flyback converters that controlled circuit with interleaving control method. According to this technique, the two switch control $\left(S W_{1}\right.$ and $\left.S W_{2}\right)$ would thus be operated in $180^{\circ}$ out of phase as illustrated in Fig. 1.

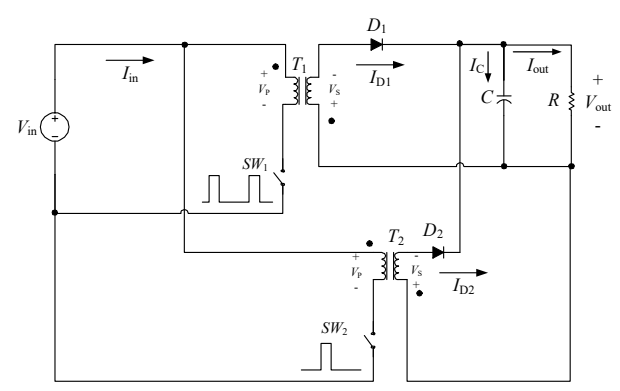

Fig. 1. Simplified schematic of modified flyback converter circuit

From Fig. 1, when $S W_{1}, S W_{2}$ are switched on, the energy is transferred from the input to the primary inductance of each transformer. In the other hand, when $S W_{1}$ and $S W_{2}$ are switched off, leads to all the energy stored in the flyback transformers are delivered to the secondary winding, capacitor and load, respectively [10]. It can be calulate the output voltage in (1). In the other way, the duty cycle $(d)$ can be obtained from (2).

$$
\begin{aligned}
& V_{\text {out }}=V_{\text {in }} \times \frac{d}{1-d} \times \frac{N_{\mathrm{S}}}{N_{\mathrm{P}}} \\
& d=\frac{(1-d) V_{\text {out }}}{V_{\text {in }}} \times \frac{N_{\mathrm{P}}}{N_{\mathrm{S}}}
\end{aligned}
$$

where: $N_{\mathrm{P}}$ is the primary winding, while $N_{\mathrm{S}}$ is corresponding to secondary winding, and also $N_{\mathrm{P}} / N_{\mathrm{S}}$ is called "transformation ratio (n)" respectively. It is observed that the duty cycle of the signal is direct proportional to the transformation ratio. Moreover, the maximum duty cycle do not provide more than $44 \%$ at high frequencies [11].

\subsection{Production cost analysis}

Generally, the production cost is, certainly, the most important cost because it determines profit and selling prices [12]. It is referred to the cost which is, absolutely, need for producing the goods. According to the LED lighting cost, the industrial has been recognized the initial cost which consist of electronic component cost, maintenance cost, transportation cost, etc. In this paper, we might, however, be only focused on the electronic component cost for mass production. Normally, there are 3 common factors for considering such cost as followed by [13]:

- Book price is a price that can find on the distributors websites such as DigiKey, Mouser, Electronic source etc. It is separated into volume levels, i.e. 1-500, or $100-1,000$ etc.

- Direct price is a price that directly quoted by the manufacturer to the original equipment manufacturer $(O E M)$, where the manufacturer has agreed to sell direct to the $O E M$. It is, generally, buy in very large volumes.

- Broken price is the most important price type for production procurement. In competitive bids, the supplier may be agree to "Break" the book price that paid by the distributor due to they can produce by using the special lower cost. This system is called "Ship from stock and debit," or "Debit".

From the above mentioned, the book price might be used for reference to pricing of commercial LED drivers circuit. However, in this paper can be calculated the pricing of LED drivers production by using the costbased pricing technique. [16] This method is setting prices $(P)$ which based on the total cost $(T C)$ and the percentage of cost $(M)$ to desire profit margins of product. It is, normally, calculated by:

$$
P=\frac{T C+M}{Q}+T C
$$

where: $M$ is called the markup percentage of cost, it is, normally, varies from $5 \%$ to more than $20 \%$ [14]

\section{Experimental Setup}

In this section, the 100 watts LED driver circuit has been designed under technique as mentioned above. However, it could be shown a block diagram in Fig.2

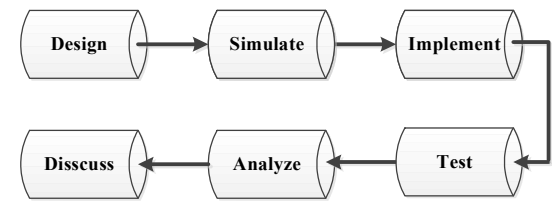

Fig. 2. Operational diagram of LED driver circuit 
From the diagram above, there are 6 main steps to develop the driver circuit. According to the designing of LED driver circuits, it has been proposed for studying the possibility of the desired circuit by starting with simulation concept. The prototype of LED driver circuit has, next, been implemented for investigation the circuit performances and analyzing the operation cost. Consequently, the reference LED driver circuit has been compared with the designed circuit for summarizing of their performances and cost. The configuration of experimental circuit has been shown in Fig. 3 .

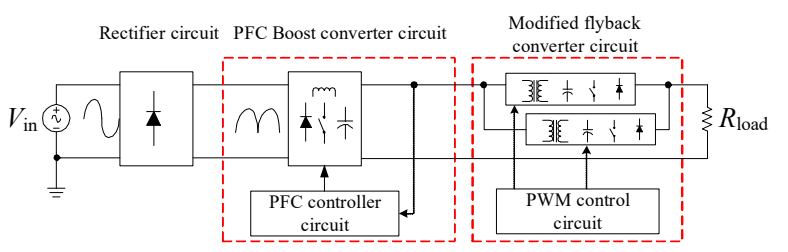

Fig. 3. Designing concept of proposed converter circuit.

According to Fig. 3, it has been divided into 2 major stages: the $P F C$ boost converter circuit and proposed converter circuit. Consequently, the $P F C$ boost converter circuit has been operated for reducing the harmonic currents and also improving the power factor of circuits. Moreover, the second stage shows the proposed circuits that has been utilized for obtaining the output power. In addition, the simulation program via LTspiceXVII programming has been employed for considering the possibility of designed circuit. After that, the prototype driver circuits have been demonstrated for characterized the performance and also production cost, respectively. Futhormore, the characterization of the driver circuit has been studied. The measurement setup has, however, been illustrated in Fig. 4

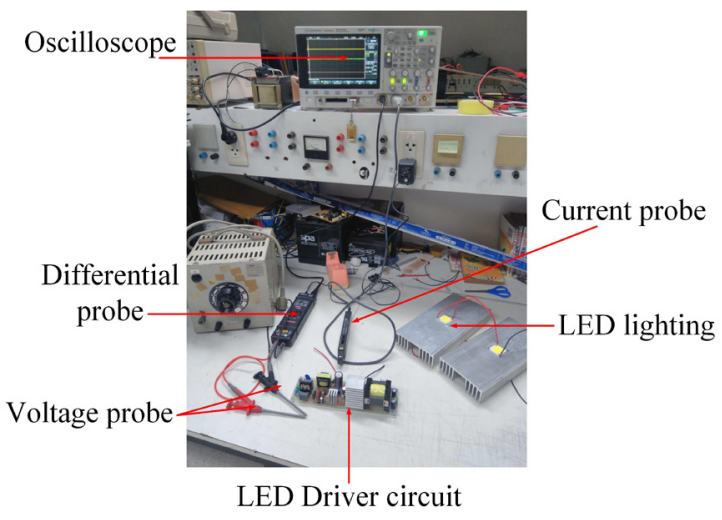

Fig. 4. Experimental setup for characterizing driver circuit

\section{Results and Discussion}

\subsection{Results of driver circuit characterization}

To ensure the designed circuit can be operated properly, the implementation has been chosen for studied the designed circuit as shown in Fig. 5(a). From the figure, we can observe that the actual designed circuit has small size with a diameter of $22 \times 6.5 \mathrm{~cm}$. Moreover, the driver circuit also has 2 small transformers for current dividing to parallel operation. This technique is an advantage over a classical flyback converter circuit.

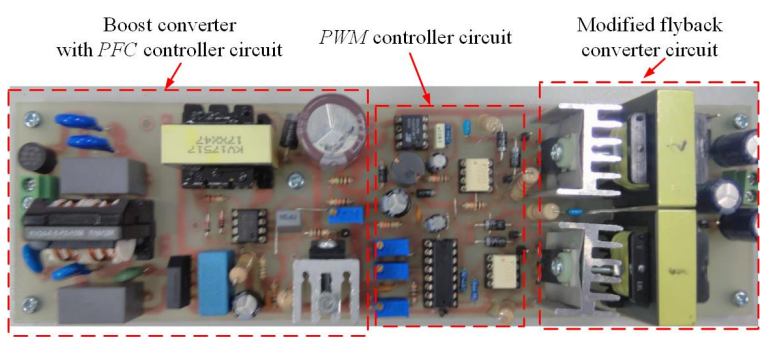

(a)

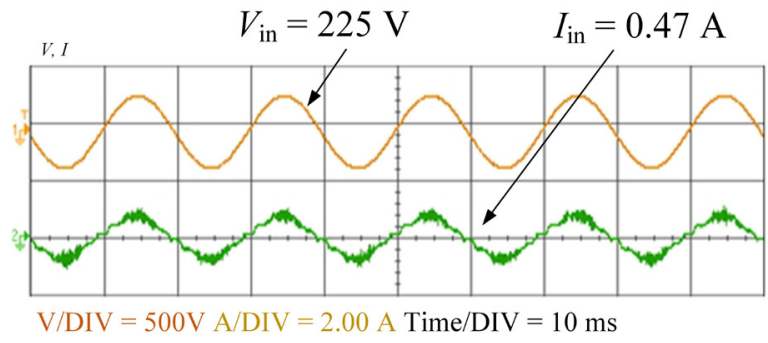

(b)

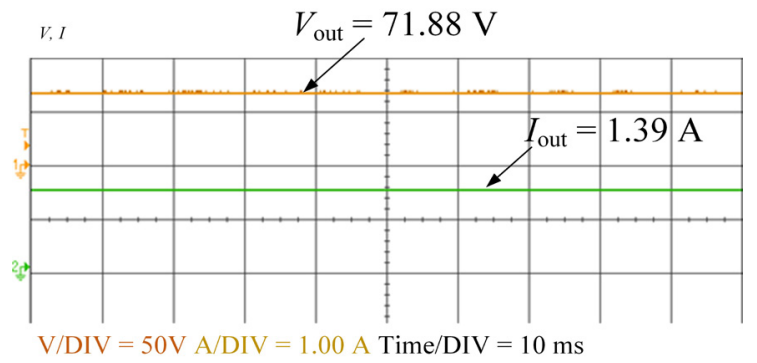

(c)

Fig. 5. Experimental result; (a) prototype circuit, (b) input voltage and input current waveforms, (c) output voltage and output current waveforms

Fig. 5(b) and 5(c) shows the input/output voltage and current which are obtained from the driver circuit. Moreover, we can observe that the input voltage $\left(V_{\text {in }}\right)$ and input current $\left(I_{\text {in }}\right)$ of 255 Volts and 0.47 Amp have been entered into the driver. Focusing on the input waveforms, we can summarize that the voltage and current waveforms are, similarly, indicated as sinusoidal waveform. In addition, it's offered approximately 0.95 of power factor $(P F)$ and also indicating the THDi of $17.03 \%$ respctively. According to Fig. 5(c), the output voltage $\left(V_{\text {out }}\right)$ of 71.88 Volts and the output current $\left(I_{\text {out }}\right)$ of 1.39 Amp has been occurred. These values obtain the output power of 99.91 Watts by calculation. The results implied that the electrical parameters that exploited from the proposed circuit is closing to the desired value that exploited from the commercial driver in any parameters. However, a summarization of the experimental electrical characteristic of the developed LED driver circuit can thus be reported on Table 1 . 
Table 1. Summerization of electrical characteristics

\begin{tabular}{|l|c|c|}
\hline \multicolumn{1}{|c|}{$\begin{array}{c}\text { Electrical } \\
\text { characteristics }\end{array}$} & $\begin{array}{c}\text { Reference } \\
\text { driver circuit }\end{array}$ & $\begin{array}{c}\text { Modified flyback } \\
\text { converter circuit }\end{array}$ \\
\hline Input voltage $\left(V_{\text {in }}\right)$ & $225 \mathrm{~V}$ & $225 \mathrm{~V}$ \\
\hline Input current $\left(I_{\text {in }}\right)$ & $0.47 \mathrm{~A}$ & $0.47 \mathrm{~A}$ \\
\hline Input power $\left(P_{\text {in }}\right)$ & $106.72 \mathrm{~W}$ & $106.36 \mathrm{~W}$ \\
\hline Output voltage $\left(V_{\text {out }}\right)$ & $71.66 \mathrm{~V}$ & $71.88 \mathrm{~V}$ \\
\hline Output current $\left(I_{\text {out }}\right)$ & $1.40 \mathrm{~A}$ & $1.39 \mathrm{~A}$ \\
\hline Output power $\left(P_{\text {out }}\right)$ & $100.32 \mathrm{~W}$ & $99.91 \mathrm{~W}$ \\
\hline Efficiency $(\eta)$ & $94 \%$ & $93.93 \%$ \\
\hline Power factor $(P F)$ & 0.96 & 0.95 \\
\hline $\begin{array}{l}\text { Total harmonic current } \\
\text { distortion }(T H D i)\end{array}$ & $17 \%$ & $17.03 \%$ \\
\hline
\end{tabular}

According to data from the table, a summarization of electrical characteristics results from prototype circuits have been acquired. Compared with the commercial driver circuit, we conclude that the performance of the modified flyback converter circuit is very similarity to the commercial circuit in any criterions.

\subsection{Results of production cost analysis}

In this section explains the calculaiton of production cost for LED driver circuit implementation. Futhermore, we could estimate the price of prototype circuits by using the cost-based pricing method. The estimaiton results can thus be detailed in Table 2 .

Table 2. Summerization of pricie of driver circuit

\begin{tabular}{|c|c|c|}
\hline Price of products & \multirow{2}{*}{ Reference driver } & $\begin{array}{c}\text { Modified flyback } \\
\text { converter circuit }\end{array}$ \\
\hline Price / unit & \multirow{2}{*}{$\sim 2,000$} & $2,953.95$ \\
\hline Price / 1,000 units & & $1,426.70$ \\
\hline Price / 10,000 units & & $1,257.17$ \\
\hline
\end{tabular}

Table II shows the price of LED driver circuit in various quantities. It can be seen that the developed prototype can, probably, be produced in the industry because of lower cost than commercial circuit. In case of 10,000 pieces, it would be observed that the modified flyback converter has the lowest cost of 1,257.17 Bath

\section{Conclusions}

This paper was presented the designing of 100 Watts LED driver circuit by using the modified flyback converter circuit. Moreover, we were investigated the circuit performances and also analyzing the investment cost by comparing with the reference circuit. The experimental results were reported that the driver efficiency was $93.93 \%$, while the implementation cost was $1,257 \mathrm{THB} / 10,000$ units. It was implied that the circuit performance was directly proportional to the driver circuit cost. However, the modified flyback converter was the most suitable for operation due to the all performances were similarity to the reference circuit. Moreover, it could be considered that the cost of the converter circuit was cheaper than the reference of
$37.15 \%$. Therefore, the usage of the designed circuits as demonstrated would thus be reduced the production cost and increasingly the large the market shared of lighting market in the future.

\section{Acknowledgement}

The authors wish to acknowledge the financial supported by the Thailand research fund $(T R F)$ and Realtronics (Thailand) Co., Ltd. (Contract No. MSD59I0022) under the research and researchers for industries (RRi) project.

\section{References}

1. E. F. Schubert., "Light-Emitting Diode," $2^{\text {nd }}$ ed., Cambridge: Cambridge University Press. 2006.

2. P. D. Teodosescu, et al., "Resonant LED Driver with Inherent Constant Current and Power Factor Correction," Electronics Letters, vol. 50, no. 15, pp. 1086-1088, 2014.

3. M. H. Chang et al., "Light Emitting Diodes Reliability Review," Microelectronics Reliability, vol. 52, no. 5, pp. 762-782, 2012.

4. J. Wu, "LED inside 2016 Southeast Asian Lighting," Market Report, 2016.

5. A. Pollock, H. Pollock, and C. Pollock. "High Efficiency LED Power Supply," IEEE Journal of Emerging and Selected Topics in Power Electronics, vol. 3, no. 3, pp. 617-623, 2015.

6. Y. Wang, "A Single-stage LED Driver for The Street Lighting System," IEEE Transl. Ind. Electron., vol. 62, no. 9, pp. 546-5457, 2015.

7. C. Cheng, and T. Y. Chung, "A Novel Single-State High-Power-Factor LED Street-Lighting Driver," IEEE Transl. Ind. Applications, vol. 50, no. 5, pp. 3037-3045, 2014.

8. M. Arias, et al., "High-Efficiency LED Driver Without Electrolytic Capacitor for Street Lighting," IEEE Transl. Ind. Applications, vol. 49, no. 1, pp. 127-137, 2013.

9. Y. Wang, et al., "A Review of LED Drivers and Related Technologies," IEEE Transl. Ind. Electron., vol. 64, no. 7, pp. 5754-5765, 2017.

10. B. Tamyurek, "An Interleaved High-Power Flyback Inverter for Photovoltaic Applications," IEEE Transl. Power Electronics, vol. 30, no. 6, pp. 32283241, 2015.

11. S. Rahayu et al., "Interleaved Flyback DC-DC Converter Design with 350 W Power Output Using LT 3757 in LT Spice," Journal of Physics: Conf. series, vol. 824, pp. 1-6, 2017.

12. C. M. Drury, "Management and Cost Accounting," Berlin: Springer, 2013.

13. D. J. Oyer, "Cost-Based Pricing," United Kingdom: Management Concepts Press., 2012.

14. G. Eric, "Sell What You Sow: the Grower's Guide to Successful Produce Marketing," $49308^{\text {th }}$ ed., California: New World Publishing, 2005. 